Check for updates

Cite this: RSC Adv., 2018, 8, 23546

\title{
Interconnecting semiconducting molecules with non-conjugated soft linkers: a way to improve film formation quality without sacrifice in charge mobility $\uparrow$
}

\author{
Wen-Jing Xiao, ${ }^{a}$ Jiandong Wang, ${ }^{a}$ Hong-Jiao Li, ${ }^{a}$ Long Liang, ${ }^{a}$ Xuan Xiang, ${ }^{a}$ \\ Xue-Qiang Chen, ${ }^{a}$ Jingjing $\mathrm{Li}^{\mathrm{b}}{ }^{\mathrm{Z}}$ Zhengquan $\mathrm{Lu}^{\mathrm{b}}$ and Wei-Shi $\mathrm{Li}$ (D) *ab
}

\begin{abstract}
The formation of high quality homogeneous active component films is essential to the fabrication of many organic optoelectronic devices, especially those having a large area module. However, most small molecule (SM) semiconductors are unable to achieve such a goal via solution processing because their large and rigid $\pi$-conjugated structures generally drive them to aggregate or crystallize into inhomogeneous domains in the process. In this work, a SM semiconductor (SM-DPP6T) based on a diketopyrrolopyrrole (DPP) center with three thiophene units on both sides encounters the same problem. However, when its molecules are interconnected with soft alkyl linkers and change into a poly(rod-coil) polymer, PRC-DPP6T, the problem is solved. Compared with SM-DPP6T, PRC-DPP6T can form a high quality homogeneous film with much better uniformity and coverage on silicon wafers by spin-coating. Moreover, the so-prepared PRC-DPP6T field-effect transistors displayed a much narrower performance distribution and comparable mobility when compared with those based on SM-DPP6T $\left(0.17 \mathrm{vs} .0 .15 \mathrm{~cm}^{2} \mathrm{~V}^{-1} \mathrm{~s}^{-1}\right)$. These results demonstrate that the interconnection of SM semiconductor molecules with soft non-conjugated linkers

is a promising way to improve film formation quality while keeping mobility intact.
\end{abstract}

Received 23rd May 2018

Accepted 21st June 2018

DOI: $10.1039 / c 8 r a 04405 h$

rsc.li/rsc-advances

\section{Introduction}

Owing to the use of organic semiconductors as key components, organic optoelectronics, such as organic field-effect transistors (OFETs), ${ }^{1-8}$ organic solar cells (OSCs), ${ }^{9-14}$ organic light-emitting diodes (OLEDs), ${ }^{15-20}$ have features of light weight, flexibility, solution processability, and adaptability in large area module fabrication, and thus cater to future demands in portable, wearable, large but light and flexible smart devices. With decades of effort, a number of high performance organic semiconductors have been designed and studied. ${ }^{1-25}$ Some of them have successfully surpassed amorphous silicon and realized a mobility larger than $1 \mathrm{~cm}^{2} \mathrm{~V}^{-1} \mathrm{~s}^{-1} \cdot^{1-8,21-30}$ Such milestone achievements in material innovation greatly drive organic electronics much closer to their practical applications. However in reality, in addition to device performance, device fabrication

${ }^{a}$ Key Laboratory of Synthetic and Self-Assembly Chemistry for Organic Functional
Molecules, Center for Excellence in Molecular Synthesis, Shanghai Institute of
Organic Chemistry, University of Chinese Academy of Sciences, Chinese Academy of
Sciences, 345 Lingling Road, Shanghai 200032, China. E-mail: liws@mail.sioc.ac.cn
${ }^{b}$ Engineering Research Center of Zhengzhou for High Performance Organic Functional
Materials, Zhengzhou Institute of Technology, 6 Yingcai Street, Huiji District,
Zhengzhou 450044, China

$\dagger$ Electronic supplementary information (ESI) available. See DOI: $10.1039 / \mathrm{c} 8 \mathrm{ra} 04405 \mathrm{~h}$ success rate is another factor that should be seriously concerned. This is of particular importance for integrated circuits having thousands and millions of component devices in one chip, since the failure of only one component will lose the entire chip. Although there are numerous factors determining and influencing the final device fabrication success rate, the capability to form a homogeneous and uniform film on a substrate for device active components (i.e. organic semiconductors) is one of the basic requirements and should be well addressed.

So far, organic semiconductors can be mainly categorized into two classes: conjugated polymers and small conjugated molecules. ${ }^{1-30}$ Conjugated polymers generally have a good potential to form a homogeneous and uniform film. But for small molecule organic semiconductors, it is often hard to achieve this goal by solution processing since they strongly tend to aggregate or crystallize into inhomogeneous domains on substrate. However, compared with conjugated polymers, small molecular semiconductors have advantages in definite structure, straightforward synthesis and purification, and no batch variation. Moreover, the performance of small molecular semiconductors still overbids that of conjugated polymers, either in the number of high performance materials or the record mobility values. ${ }^{1-8,21-30}$ In an important comprehensive review article written by $\mathrm{Hu}$, et al., ${ }^{3}$ over 700 small molecular semiconductor $\pi$-conjugated systems including $438 \mathrm{p}$ type and 205 n-type have been highlighted. But only 66 
conjugated polymer semiconductors have been introduced. To the best of our knowledge, the record hole mobility for small molecular semiconductors to date is $43 \mathrm{~cm}^{2} \mathrm{~V}^{-1} \mathrm{~s}^{-1}$, achieved by a rubrene crystal, ${ }^{31}$ much higher than that for conjugated polymers $\left(23.7 \mathrm{~cm}^{2} \mathrm{~V}^{-1} \mathrm{~s}^{-1}\right.$ achieved by aligned PCDTPT ${ }^{32}$ ). In addition, many p-type semiconductor compounds have been reported to have hole mobility exceeding $30 \mathrm{~cm}^{2} \mathrm{~V}^{-1} \mathrm{~s}^{-1} \cdot{ }^{26,33}$ For n-type small molecular semiconductors, the best performance was reported by Pei's group, who developed $\mathrm{F}_{4}$-BDOPV and obtained an ambientstable mobility of $12.6 \mathrm{~cm}^{2} \mathrm{~V}^{-1} \mathrm{~s}^{-1} .{ }^{29}$ This is still larger than that for conjugated polymers $\left(6.50 \mathrm{~cm}^{2} \mathrm{~V}^{-1} \mathrm{~s}^{-1}\right) \cdot{ }^{34}$ Thus, it is of significance to study how to improve film formation capability of small molecular semiconductors while keeping their merits intact. In 2014, we reported a poly(rod-coil) strategy, which can change small photovoltaic molecules into polymeric materials by interconnecting them with non-conjugated segments. ${ }^{35}$ We demonstrated that the newly formed poly(rod-coil) materials show a photovoltaic performance less dependent on their molecular weights, since they possess identical core photoactive conjugated segment structure irrespective of their polymeric degrees. In a succeeding work, we proved that poly(rod-coil) polymers have a good film formation capability than their small molecular reference. ${ }^{36,37}$ In this work, we further apply this strategy on a small organic transistor, SM-DPP6T, and interconnect its molecules by butylene segments (Scheme 1). It is found that this approach can significantly improve film formation quality, and thus greatly enhance device fabrication success rate for OFET. Moreover, the newly synthesized poly(rod-coil) semiconductor (PRC-DPP6T) displayed an optimized field-effect mobility of $0.17 \mathrm{~cm}^{2} \mathrm{~V}^{-1} \mathrm{~s}^{-1}$, which is comparable to that of SM-DPP6T $\left(0.15 \mathrm{~cm}^{2} \mathrm{~V}^{-1} \mathrm{~s}^{-1}\right)$. Therefore, the present work well exemplifies the poly(rod-coil) approach would be a promising way for SM semiconductors to improve film formation quality but without sacrifice in device performance. It is valuable to point out that this approach is somewhat different from so-called "conjugation-break" strategy, ${ }^{38-43}$ which is aimed to modify the properties of conjugated polymer semiconductors by inserting non-conjugated soft linkers into the polymer backbone.
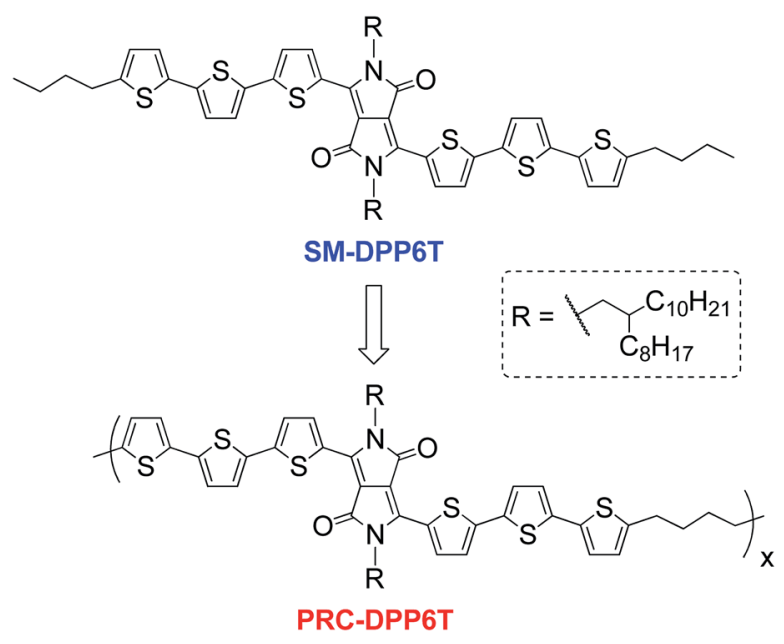

Scheme 1 Chemical structures of SM-DPP6T and PRC-DPP6T.

\section{Experimental section}

\section{Materials and characterization methods}

The syntheses of SM-DPP6T and PRC-DPP6T are shown in Scheme 2 and experimental details can be found in the ESI. $\dagger$

\section{Device fabrication and characterization}

A bottom-gate-top-contact OFET device configuration was used to characterize charge transport properties of SM-DPP6T and PRC-DPP6T. Devices were fabricated on heavily $\mathrm{p}^{+}$-doped $\mathrm{Si}$ wafers with a thermally grown silicon oxide layer $(\sim 300 \mathrm{~nm})$ having a resistivity of $0.005-0.020 \mathrm{ohm} \mathrm{cm}$, in which $\mathrm{p}^{+}-\mathrm{Si}$ served as gate electrode while the silicon oxide layer acted as gate dielectric. Prior to use, $\mathrm{SiO}_{2} / \mathrm{Si}$ wafers were first cleaned by ultrasonication in deionized water for $5 \mathrm{~min}$, and then subjected to the treatment with a Piranha solution composed of $2 / 1$ (v/v) $\mathrm{H}_{2} \mathrm{SO}_{4}$ and $\mathrm{H}_{2} \mathrm{O}_{2}$ at $90{ }^{\circ} \mathrm{C}$ for $15 \mathrm{~min}$. After washed with deionized water for three times, the wafers were further cleaned by sequential ultrasonications in de-ionized water, acetone, and isopropanol for $5 \mathrm{~min}$ in each step. Then, the wafers were dried with nitrogen flow and heating at $90{ }^{\circ} \mathrm{C}$ for $1 \mathrm{~h}$ under vacuum. Afterwards, octadecyltrichlorosilane (OTS) treatment was carried out by dropping a few OTS drops on wafer surfaces and placing in an oven at $120{ }^{\circ} \mathrm{C}$ for $3 \mathrm{~h}$ under vacuum. After sequentially cleaned by ultrasonication in chloroform, heptane, acetone, and isopropanol for $5 \mathrm{~min}$ each, the wafers were dried again using nitrogen flow. Onto these OTS-treated wafers, the active layers were fabricated by spin-coating chlorobenzene solutions of PRC-DPP6T and SM-DPP6T (5 $\left.\mathrm{mg} \mathrm{mL}^{-1}\right)$ at $2000 \mathrm{rpm}$ for $30 \mathrm{~s}$ under ambient conditions. Source/drain contacts (50 nm-thick gold) were then deposited by vacuum deposition through a shadow mask and finished the device fabrication. The so-prepared devices had a channel length $(L)$ of $273 \mu \mathrm{m}$ and a channel width $(W)$ of $31 \mu \mathrm{m}$. If needed, thermal annealing was performed on devices at desired temperature for 30 min under nitrogen.

The evaluation of transistor performance was carried out under ambient conditions using a Keithley 4200 semiconductor characterization system. The carrier mobility in the saturated regime, $\mu_{\text {sat }}$, is calculated according to the below equation:

$$
I_{\mathrm{DS}}=C_{\mathrm{i}} \mu_{\mathrm{sat}}(W / 2 L)\left(V_{\mathrm{G}}-V_{\mathrm{T}}\right)^{2}
$$

where $I_{\mathrm{DS}}$ is drain current; $W$ and $L$ are semiconductor channel width and length, respectively; $C_{\mathrm{i}}$ is capacitance per unit area of the gate dielectric; and $V_{\mathrm{G}}$ and $V_{\mathrm{T}}$ are gate and threshold voltages, respectively. Device $V_{\mathrm{T}}$ was determined from extrapolation of the linear fit of the $\left(I_{\mathrm{DS}}\right)^{1 / 2}$ versus $V_{\mathrm{G}}$ curve in the saturation regime at $I_{\mathrm{DS}}=0$.

\section{Results and discussions}

As shown in Scheme 2, the synthesis of PRC-DPP6T was started from $2,2^{\prime}$-bithiophene. It was lithiated with $n$-BuLi and further reacted with 1,4-dibromobutane, affording 1,4-butylene-linked bis(2,2'-bithiophene). Then, the compound was stannylated with the aid of $n$-BuLi and converted into one of important 


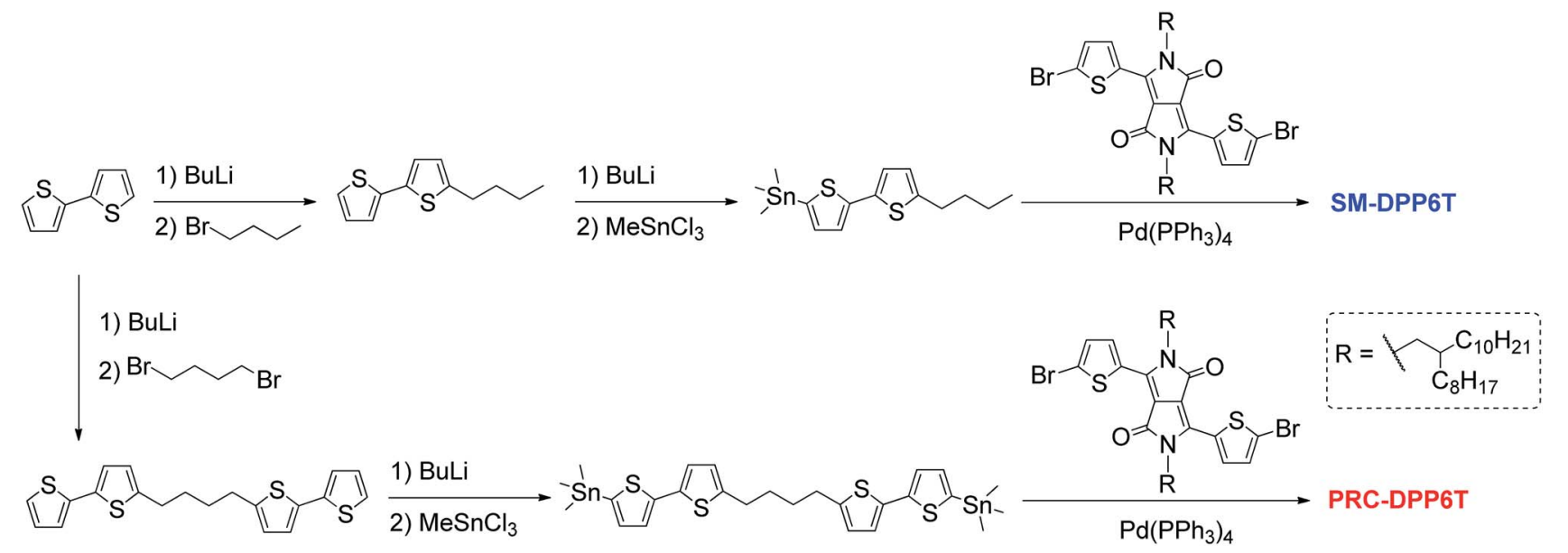

Scheme 2 Synthetic routes of SM-DPP6T and PRC-DPP6T.

monomers for PRC-DPP6T synthesis. Finally, this monomer was Stille-coupling polymerized with 3,6-bis(5-bromothienyl)1,4-diketopyrrolo[3,4-c]pyrrole. The obtained crude polymer was purified by Soxhlet solvent extraction with methanol, hexane, acetone and chloroform subsequently and finally subjected to size-exclusion chromatography using a column packed with Bio-Bead S-X1 beads to discard low molecular weight fraction. The finally afforded PRC-DPP6T polymer was found to have a number-average molecular weight $\left(M_{\mathrm{n}}\right)$ of $14.4 \mathrm{kDa}$ and a polydispersity index $(\theta)$ of 1.98 (Fig. S6 $\dagger$ ). Meanwhile, the small molecular reference compound, SM-DPP6T, was prepared by the similar Stille coupling reaction and structurally identified by ${ }^{1} \mathrm{H}$ NMR (Fig. S7†), ${ }^{13} \mathrm{C}$ NMR (Fig. S8 $\dagger$ ), and mass spectroscopy (Fig. S9†).

Thermogravimetric analysis (TGA) and differential scanning calorimetry (DSC) were used to evaluate thermal properties of PRC-DPP6T and SM-DPP6T. It is found that both PRC-DPP6T and SM-DPP6T possess good thermal stability under $\mathrm{N}_{2}$ atmosphere, with 5\%-weight-loss decomposition temperature $\left(T_{\mathrm{d}}\right)$ above $400{ }^{\circ} \mathrm{C}$ (Fig. S10 $\dagger$ and Table 1). In the second heatingcooling cycle of DSC measurement (Fig. 1a and Table 1), a sharp endothermic peak at $131{ }^{\circ} \mathrm{C}$ and an intense exothermic peak at $104^{\circ} \mathrm{C}$ were observed for SM-DPP6T. Optical microscopy further confirmed that these phase transitions are melting and thermal crystallization process respectively. This indicates that SMDPP6T, like most reported small molecular semiconductors, is a crystalline material at room temperature. Of interest, a melting transition around $167^{\circ} \mathrm{C}$ and a thermal crystallizing transition around $160{ }^{\circ} \mathrm{C}$ still appeared in the DSC profile of PRC-DPP6T during heating and cooling processes, respectively. Moreover, an additional exothermic peak around $64{ }^{\circ} \mathrm{C}$ may be assignable to glass transition induced by side chain solidification. This complicate phase-transition behaviour suggests that PRC-DPP6T does not resemble conventional 1,4-diketopyrrolo $[3,4-c]$ pyrrole (DPP)-based conjugated polymers, in which no any thermal transitions were observed in the most cases. ${ }^{44-48}$ The presence of melting/thermal crystallization transition provides the material a potential of melt processing in device fabrication. Since no any solvent is involved, such processing technology is simple, cost-effective, and environmentally benign, and thus extremely welcomed in industry.

Fig. 1b displays UV-vis absorption spectra of PRC-DPP6T and SM-DPP6T in solution and film state with their absorption peaks summarized in Table 1. In dilute chlorobenzene (CB) solution, SM-DPP6T showed an intense absorption spectrum in the range of $300-700 \mathrm{~nm}$ with peak-tops at 653,614 , and $388 \mathrm{~nm}$. Concentration-dependent UV-vis spectroscopy (Fig. S11 $\dagger$ ) revealed that the absorbance of these peaks obey Beer-Lambert law very well, indicating all these peaks originate from single molecule of SM-DPP6T. With further reference to literature reports, ${ }^{49-52}$ the peaks at 653 and $614 \mathrm{~nm}$ can be assignable to $0-0$ and $0-1$ vibration bands of intramolecular charge transfer (ICT) between DPP accepting unit and oligothiophene donor moieties, while the peaks around $388 \mathrm{~nm}$ are due to local $\pi-\pi^{*}$ transitions. In film state, the ICT peaks hypochromatically shifted to 633 and $586 \mathrm{~nm}$. Meanwhile,

Table 1 Basic physical properties of PRC-DPP6T and SM-DPP6T

\begin{tabular}{|c|c|c|c|c|c|c|c|c|c|}
\hline & \multirow[b]{2}{*}{$T_{\mathrm{d}}\left({ }^{\circ} \mathrm{C}\right)$} & \multirow[b]{2}{*}{$T_{\mathrm{m}}\left({ }^{\circ} \mathrm{C}\right)$} & \multicolumn{2}{|l|}{$\lambda_{\max }(\mathrm{nm})$} & \multirow[b]{2}{*}{$\lambda_{\text {film,onset }}(\mathrm{nm})$} & \multirow[b]{2}{*}{$E_{\mathrm{g}, \mathrm{opt}}{ }^{a}(\mathrm{eV})$} & \multirow[b]{2}{*}{$E_{\text {ox }, \text { onset }}\left(V v s . \mathrm{Ag} / \mathrm{Ag}^{+}\right)$} & \multirow[b]{2}{*}{$E_{\text {номо }}^{b}(\mathrm{eV})$} & \multirow[b]{2}{*}{$E_{\text {LUMO }}^{c}(\mathrm{eV})$} \\
\hline & & & Solution & Film & & & & & \\
\hline PRC-DPP6T & 410 & 167 & $\begin{array}{l}390,620 \\
664\end{array}$ & $\begin{array}{l}413,645 \\
712,823\end{array}$ & 877 & 1.41 & 0.57 & -5.27 & -3.83 \\
\hline
\end{tabular}



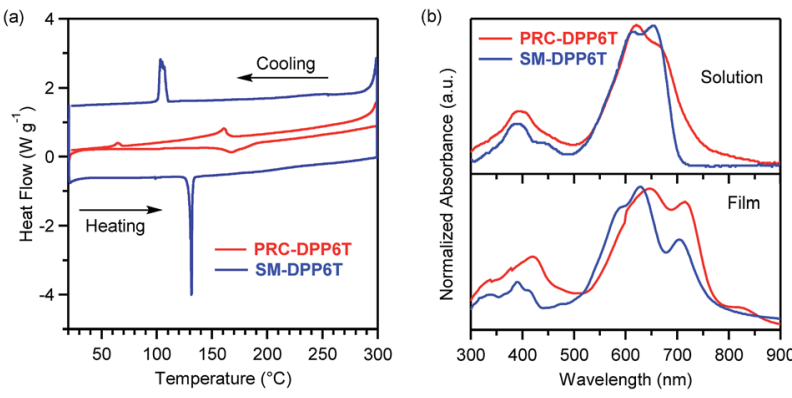

Fig. 1 (a) The second heating/cooling traces in DSC profiles of PRCDPP6T and SM-DPP6T at a temperature ramping rate of $10{ }^{\circ} \mathrm{C} \mathrm{min}-1$ under $\mathrm{N}_{2}$ atmosphere, (b) normalized UV-vis absorption spectra of PRC-DPP6T and SM-DPP6T in chlorobenzene solution and film state.

a new absorption peak at $704 \mathrm{~nm}$ was observed, which would come from intermolecular $\pi-\pi$ stacking interactions. All these spectral changes suggest that SM-DPP6T forms H-aggregates ${ }^{53}$ in solid state. Compared with SM-DPP6T, PRC-DPP6T displayed a similar ICT band in solution but in slightly red-shifted region with two peak-tops at 664 and $620 \mathrm{~nm}$ and a larger FWHM (full width at half maximum). Although concentration-dependent spectroscopy (Fig. S11 $\dagger$ ) again confirms that these absorption features are coming from single chain of the polymers, the red shifts in peaktops and the broadness of ICT band implies the existence of certain specific interactions among conjugated segments of single strand polymer even in diluted solution. In film state, these ICT peaks of PRC-DPP6T changed to 712 and $645 \mathrm{~nm}$, having a red shift of 48 and $25 \mathrm{~nm}$, respectively, as reference to their solution spectrum. Moreover, a new peak corresponding to $\pi-\pi$ interactions among conjugated segments from different or even the same polymer chains appeared at $823 \mathrm{~nm}$ in film state. These observations indicate that PRCDPP6T, unlike SM-DPP6T, undergoes J-aggregation ${ }^{53}$ in solid state. Furthermore, such contrary spectral shifts of PRC-DPP6T and SM-DPP6T in film state also afforded quite difference in onset absorption point, in which that of PRC-DPP6T $(877 \mathrm{~nm})$ is about $100 \mathrm{~nm}$ red-shifted to that of SM-DPP6T $(764 \mathrm{~nm})$. As a result, PRC-DPP6T showed a slightly narrower bandgap than SM-DPP6T (1.41 vs. $1.62 \mathrm{eV})$.

Cyclic voltammetry (CV, Fig. S12 $\dagger$ ) was used to evaluate electronic energy levels of PRC-DPP6T and SM-DPP6T. Both materials displayed an intense oxidative peak in the positive scanning with an onset point of 0.57 and $0.64 \mathrm{~V} v s$. $\mathrm{Ag} / \mathrm{Ag}^{+}$for PRC-DPP6T and SM-DPP6T, respectively (Table 1). Based on the facts that the absolute energy level of ferrocene/ferrocenium $\left(\mathrm{Fc} / \mathrm{Fc}^{+}\right)$is $-4.80 \mathrm{eV}$ from vaccum ${ }^{54-56}$ and its redox couple $\left(E_{\mathrm{Fc} / \mathrm{Fc}^{+}}\right)$was estimated to be $0.098 \mathrm{~V}$ under the same conditions, the highest occupied molecular orbital (HOMO) energy levels of PRC-DPP6T and SM-DPP6T were calculated to be -5.27 and $-5.34 \mathrm{eV}$, respectively. From these HOMO and previous optical bandgap data, the energy level of the lowest unoccupied molecular orbital (LUMO) was estimated to be $-3.83 \mathrm{eV}$ for PRC-DPP6T and $-3.72 \mathrm{eV}$ for SM-DPP6T. Therefore, both materials possess similar electronic energy levels with low-lying HOMO and LUMO levels, indicating both of them have potential to be used as hole- and electro-conducting semiconductors.
Film formation capability is critical to a material for achieving high device fabrication rate. In this work, we evaluated this capability of PRC-DPP6T and SM-DPP6T by spincoating their chlorobenzene (CB), chloroform (CF), and $o^{-}$ dichlorobenzene $(o$-DCB) solutions with a concentration of $5 \mathrm{mg} \mathrm{mL}{ }^{-1}$ onto octadecyltrichlorosilane (OTS)-treated $\mathrm{SiO}_{2} / \mathrm{Si}$ wafers. Optical microscopy (OM) found that PRC-DPP6T can form a smooth film irrespective of which solvent was used (Fig. 2). Raman reflective mapping at $1516 \mathrm{~cm}^{-1}$ on three different areas further confirmed the homogeneous distribution of PRC-DPP6T on these films (Fig. 2). In sharp contrast, many aggregates were found in OM pictures of SM-DPP6T films spin-coating from its $\mathrm{CB}$ or CF solution. Raman reflective mapping further demonstrated uneven distribution of SMDPP6T on these films. Moreover, when $o$-DCB was used as solvent, all attempts to form a naked eye-distinguished SMDPP6T film failed (Fig. 2). All these experiments clearly indicate that PRC-DPP6T possesses a much better film formation capability than SM-DPP6T.

In order to quantitatively identify the difference in this film formation capability; we statistically investigated surface coverage on $\sim 50$ piece samples prepared from CB solutions (Fig. 3a). The parameter of surface coverage was estimated by comparing the total area of the surface having sample on it to the whole surface area of the $\mathrm{SiO}_{2} / \mathrm{Si}$ wafer $\left(\sim 10 \times 10 \mathrm{~mm}^{2}\right)$. Of interest, it was found that all the checked PRC-DPP6T samples possessed a fully covered surface. However, only 20\% SMDPP6T samples displayed a surface coverage larger than $95 \%$, and as large as $46 \%$ SM-DPP6T samples had a surface coverage less than 5\%. Obviously, samples with a surface coverage less than $95 \%$ could not produce qualified OFET devices in practice and thus are not applicable for device fabrication. Therefore in this work, only the samples having a surface coverage of $>95 \%$ were used for OFET device fabrication. After checking the performances of these as-prepared OFETs, we got a distribution in mobility of SM-DPP6T devices, ranging from 0.002 to 0.055 $\mathrm{cm}^{2} \mathrm{~V}^{-1} \mathrm{~s}^{-1}$ (Fig. 3b). This distribution became narrow into a range of $0.002-0.012 \mathrm{~cm}^{2} \mathrm{~V}^{-1} \mathrm{~s}^{-1}$ in the case of PRC-DPP6T. The result is not surprising since it is closely associated with the aforementioned uneven surface coverage for SM-DPP6T on modified $\mathrm{SiO}_{2} / \mathrm{Si}$. Again, it confirms poly(rod-coil) polymer, PRC-DPP6T, possesses better film formation property than SMDPP6T, and thus has a much higher potential to produce qualified OFET devices and with reproducible performance.

Although PRC-DPP6T displayed much better film formation properties and showed a high device fabrication success rate than SM-DPP6T, the best performance of its as-prepared devices lagged behind SM-DPP6T devices. Since device performance is highly dependent on molecular $\pi-\pi$ packing in the active layer, step thermal annealing was applied on both SM-DPP6T and PRC-DPP6T devices to optimize such packing structures (Fig. 3c, Table 2, Fig. S13 and S14 $\dagger$ ). Initially, the as-prepared SM-DPP6T device exhibited a mobility of $0.054 \mathrm{~cm}^{2} \mathrm{~V}^{-1} \mathrm{~s}^{-1}$. Its mobility was gradually enhanced to 0.079 and $0.13 \mathrm{~cm}^{2} \mathrm{~V}^{-1}$ $\mathrm{s}^{-1}$ after step thermal annealing at $60{ }^{\circ} \mathrm{C}$ and $80{ }^{\circ} \mathrm{C}$ for $30 \mathrm{~min}$, respectively. The best performance was achieved after further annealing at $100{ }^{\circ} \mathrm{C}$ for $30 \mathrm{~min}$ and reported a mobility of 0.15 
(a)
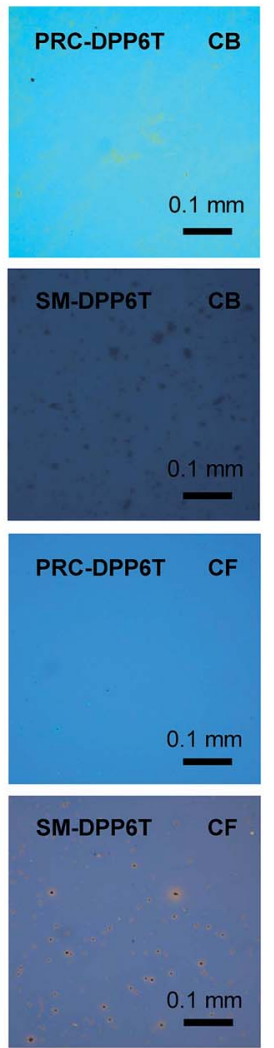

PRC-DPP6T o-DCB (b)
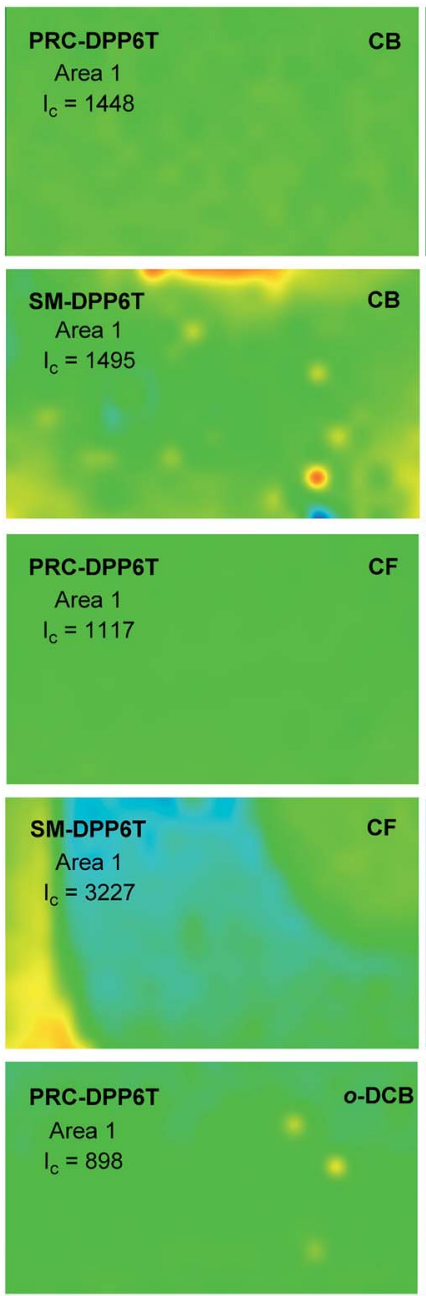
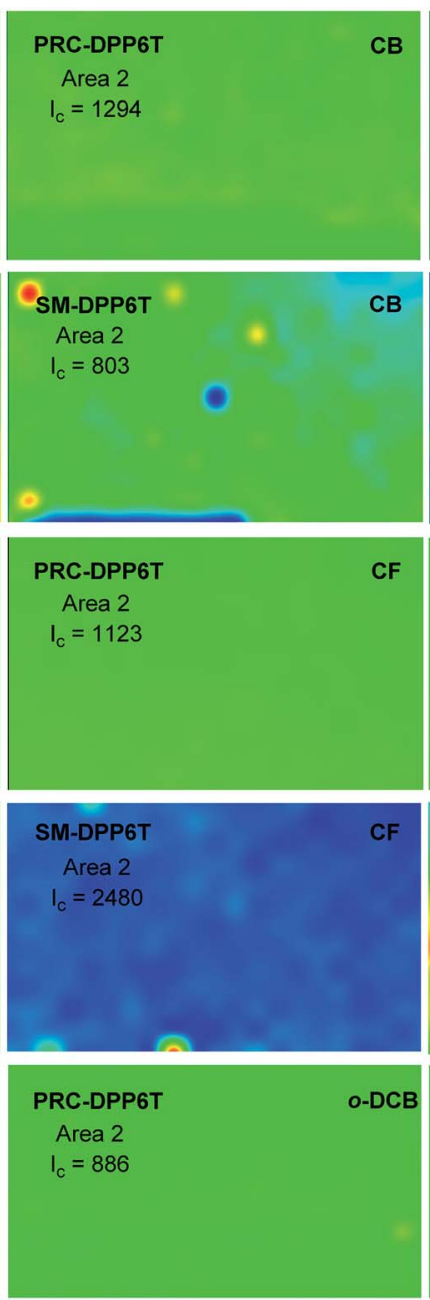
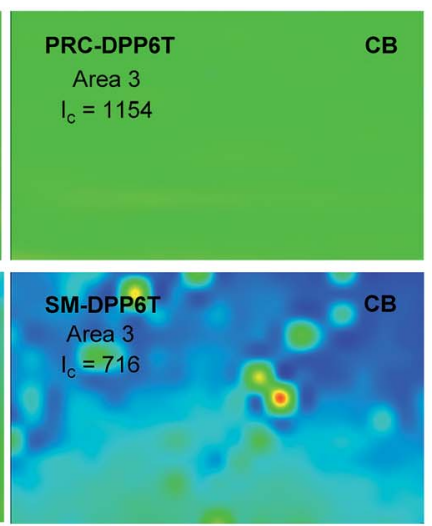

$\mathrm{I}_{\mathrm{c}}+700$
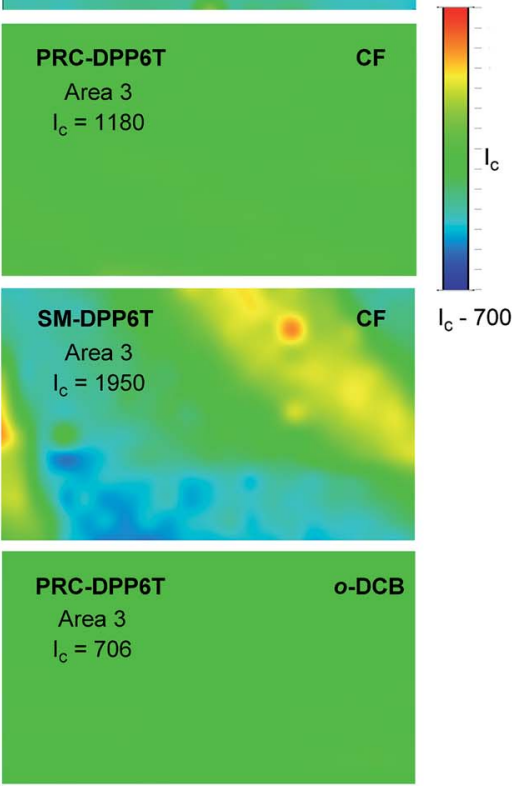

Fig. 2 (a) Optical microscope images, (b) reflective Raman mapping $\left(600 \times 360 \mu \mathrm{m}^{2}\right)$ at $1516 \mathrm{~cm}^{-1}$ of PRC-DPP6T and SM-DPP6T films spincoated from various solutions. The parameter $I_{c}$ in $(b)$ is the average Raman intensity between the largest and the smallest values for the mapping area.

$\mathrm{cm}^{2} \mathrm{~V}^{-1} \mathrm{~s}^{-1}$. However, when the device was further annealed at $120{ }^{\circ} \mathrm{C}$, its mobility quickly dropped to $0.034 \mathrm{~cm}^{2} \mathrm{~V}^{-1} \mathrm{~s}^{-1}$. In comparison, PRC-DPP6T device displayed an initial mobility of $0.0054 \mathrm{~cm}^{2} \mathrm{~V}^{-1} \mathrm{~s}^{-1}$, one order lower than that of SM-DPP6T device. Step thermal annealing also improve device performance gradually and finally reached $0.17 \mathrm{~cm}^{2} \mathrm{~V}^{-1} \mathrm{~s}^{-1}$ after annealing at $180{ }^{\circ} \mathrm{C}$. This value is comparable to that of SMDPP6T device $\left(0.15 \quad \mathrm{~cm}^{2} \quad \mathrm{~V}^{-1} \mathrm{~s}^{-1}\right)$. Further rising the (a)

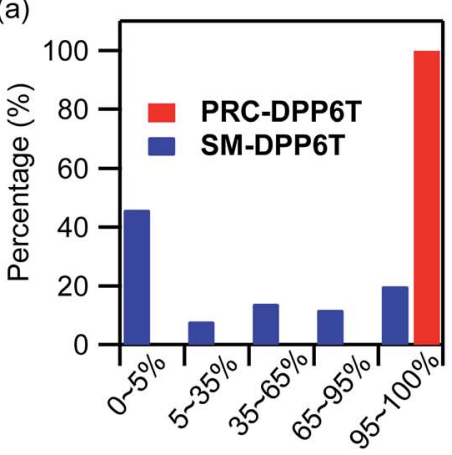

(b)

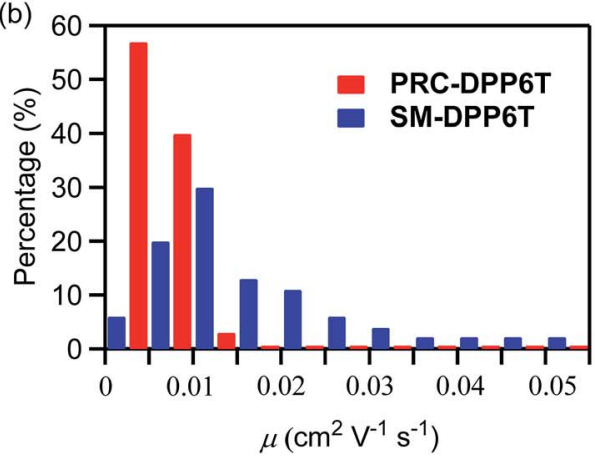

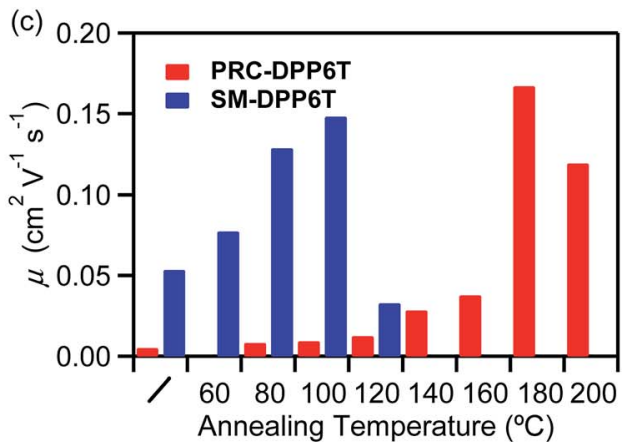

Fig. 3 (a) Surface coverage distributions of $\sim 50$ pieces samples; (b) hole mobility distributions of $\sim 30$ devices of PRC-DPP6T and SM-DPP6T films prepared from spin-coating their $\mathrm{CB}$ solutions onto OTS-treated $\mathrm{SiO}_{2} / \mathrm{Si}$ wafers; (c) mobility changes of their best devices subjected to thermal annealing at various temperatures. 
Table 2 Performance of as-cast and step-annealed PRC-DPP6T and SM-DPP6T OFET devices

\begin{tabular}{|c|c|c|c|c|}
\hline Devices & $T_{\text {annealing }}\left({ }^{\circ} \mathrm{C}\right)$ & $\mu_{\max }\left(\mu_{\mathrm{avg}}\right)^{a}\left(\mathrm{~cm}^{2} \mathrm{v}^{-1} \mathrm{~s}^{-1}\right)$ & $I_{\mathrm{on}} / I_{\mathrm{off}}$ & $V_{\mathrm{Th}, \text { avg }}(\mathrm{V})$ \\
\hline PRC-DPP6T & $-^{b}$ & $0.0054(0.0046)$ & $10^{4}-10^{5}$ & -6.83 \\
\hline & 80 & $0.0086(0.0063)$ & $10^{4}-10^{5}$ & -6.90 \\
\hline & 120 & $0.013(0.011)$ & $10^{4}-10^{5}$ & -16.14 \\
\hline & 140 & $0.029(0.023)$ & $10^{5}-10^{6}$ & -13.59 \\
\hline & 160 & $0.038(0.028)$ & $10^{5}-10^{6}$ & -9.27 \\
\hline \multirow[t]{5}{*}{ SM-DPP6T } & $-b$ & $0.054(0.039)$ & $10^{3}-10^{4}$ & -13.02 \\
\hline & 60 & $0.079(0.068)$ & $10^{4}-10^{5}$ & -8.03 \\
\hline & 80 & $0.13(0.12)$ & $10^{4}-10^{5}$ & -10.16 \\
\hline & 100 & $0.15(0.13)$ & $10^{4}-10^{5}$ & -10.22 \\
\hline & 120 & $0.034(0.024)$ & $10^{4}-10^{5}$ & -2.41 \\
\hline
\end{tabular}

${ }^{a}$ Data in parenthesis are average values based on around 12 devices. ${ }^{b}$ As cast devices.

temperature to $200{ }^{\circ} \mathrm{C}$ led to slightly dropping its mobility to $0.12 \mathrm{~cm}^{2} \mathrm{~V}^{-1} \mathrm{~s}^{-1}$. This result is interesting when considering PRC-DPP6T device initially showed a poor performance than SM-DPP6T device, but finally overbid the latter after thermal annealing. More importantly, the PRC-DPP6T device achieved its best performance at a temperature of $180{ }^{\circ} \mathrm{C}$, much higher than that for small molecule-based device $\left(100{ }^{\circ} \mathrm{C}\right)$, implying the device of PRC-DPP6T would possess a much higher heatresistant property than that based on SM-DPP6T.

In order to understand the changes in chain/molecular packing structure, $\pi-\pi$ interactions, and film morphology during step thermal annealing processes, X-ray diffraction (XRD), temperature-dependent UV-vis absorption spectroscopy, and atomic force microscopy (AFM) were carried out. As shown in Fig. 4b, the as-casted SM-DPP6T film exhibited a set of diffraction peaks at $4.47,9.02$, and $18.28^{\circ}$ having $d$-spacing of $1.974,0.979$, and $0.485 \mathrm{~nm}$, respectively. These peaks can be assigned to 100, 200 and 400 diffraction of a lamellar structure with a layer distance of $1.97 \mathrm{~nm}$. Besides these peaks, a broad and weak peak appeared at $22.9^{\circ}$ with a $d$-spacing of $0.39 \mathrm{~nm}$, which comes from 010 diffraction and suggests the existence of face-to-face $\pi-\pi$ stacking among molecules. When the film was subjected to step annealing, the 100 peak became more and more sharp and slight shifted to small diffraction angle. Moreover, after annealing at $100{ }^{\circ} \mathrm{C}$, the film clearly displayed a set of new diffraction peaks around 10.24 and $20.68^{\circ}$ with $d$-spacing of 0.86 and $0.43 \mathrm{~nm}$, respectively, suggesting the possibly rising of new order in a new crystalline dimension. All these observations indicate that thermal annealing improves the crystalline order of SM-DPP6T, and thus account for its performance improvement in charge transportation. In comparison, the XRD profile of as-casted PRCDPP6T film shows a set of diffraction peaks at 6.0,12.0, and $17.6^{\circ}$ with $d$-spacing of $1.47,0.74$, and $0.50 \mathrm{~nm}$, respectively (Fig. 4a). These also suggest the chains of PRC-DPP6T formed a lamellar structure with layer distance of $1.47 \mathrm{~nm}$. When the film was subjected to stepwise thermal annealing at 80, 100, 120, and $140{ }^{\circ} \mathrm{C}$, the 100 peak became broader and broader. Further thermal annealing at 160,180 and $200{ }^{\circ} \mathrm{C}$ resulted in the rising of a new peak at $5.5^{\circ}$ and the vanish of the peak around $6.6^{\circ}$, implying the reorganization in its chain packing structure under such high temperature annealing. However, all these can't well explain the performance improvement for PRC-DPP6T film after thermal annealing. Fortunately, besides these changes, a broad peak around $22.3^{\circ}$ appeared after $120{ }^{\circ} \mathrm{C}$ annealing and kept clearly visible even after $200{ }^{\circ} \mathrm{C}$ annealing. This peak has a $d$ spacing of $0.40 \mathrm{~nm}$ and could be closely associated to $\pi-\pi$ stacking structure among the polymer chains. Therefore, it indicates that thermal annealing promotes PRC-DPP6T chains form a more favourable regular packing structure to facilitate the occurrence of $\pi-\pi$ interactions, and thus improves its OFET performance.
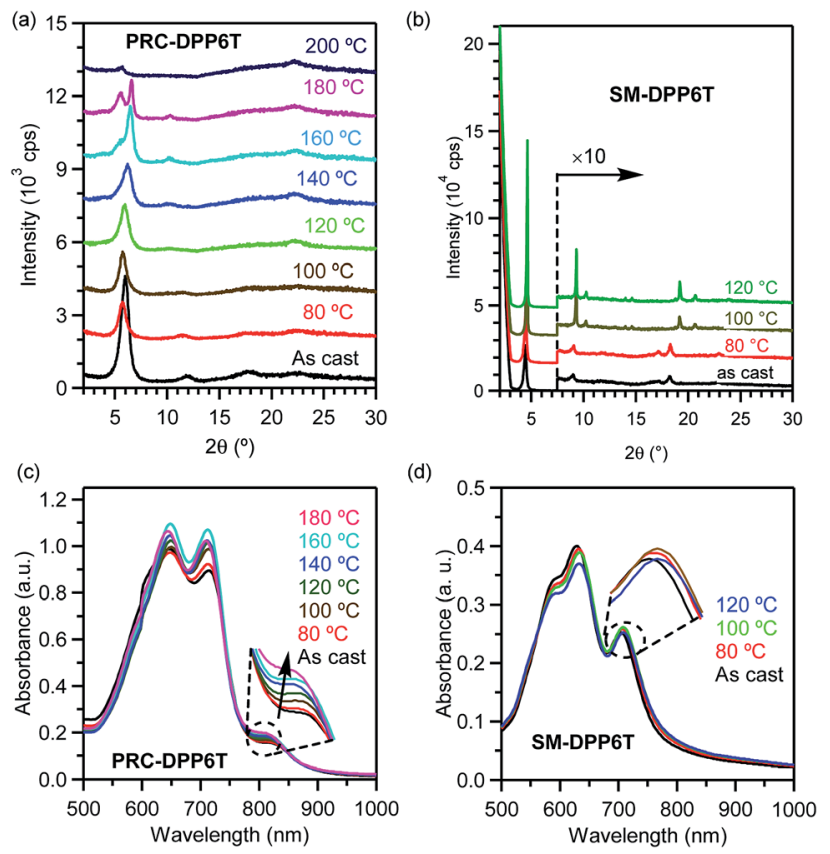

Fig. 4 (a and b) XRD profiles of (a) PRC-DPP6T and (b) SM-DPP6T films on OTS-modified $\mathrm{Si} / \mathrm{SiO}_{2}$ wafers in as-cast condition and after thermal annealing at various temperatures. (c and d) UV-vis absorption spectra of (c) PRC-DPP6T and (d) SM-DPP6T films on quartz plates in as-cast condition and after thermal annealing at various temperatures. Insets show their enlarged regions for $\pi-\pi$ interactions. 

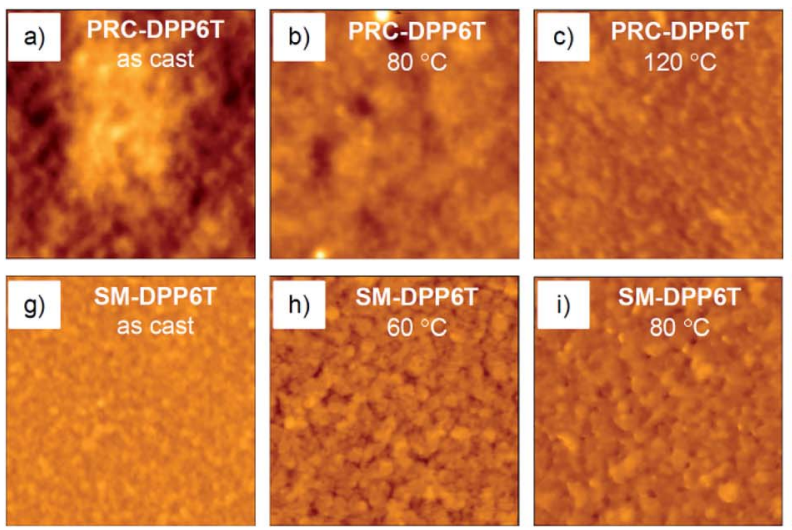
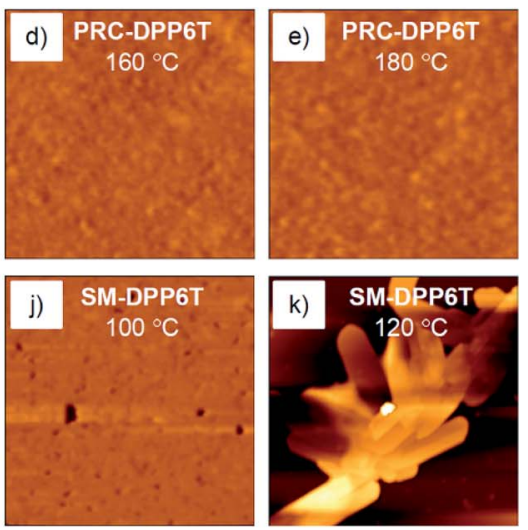

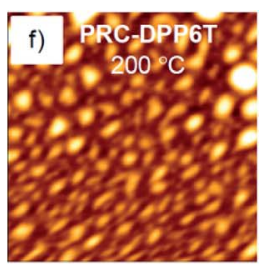

$60 \mathrm{~nm}$

Fig. 5 AFM topographical height images $\left(5 \times 5 \mu \mathrm{m}^{2}\right)$ of $(\mathrm{a}-\mathrm{f}) \mathrm{PRC}$-DPP6T and $(\mathrm{g}-\mathrm{k}) \mathrm{SM}$-DPP6T films on OTS-treated Si/SiO ${ }_{2}$ wafers after annealing at various temperatures.

Fig. 4c and d display UV-vis absorption spectra of PRCDPP6T and SM-DPP6T films upon step thermal annealing. It is found that the absorbance of $\pi-\pi$ interaction peak for PRCDPP6T (around $823 \mathrm{~nm}$ ) increased with the elevation of thermal annealing temperature. This indicates thermal annealing can promote $\pi-\pi$ interactions among conjugated segments in PRC-DPP6T. But in the case of SM-DPP6T, the situation became a little complicated. When the film was step annealed at $80{ }^{\circ} \mathrm{C}$ and then $100{ }^{\circ} \mathrm{C}$, the absorbance of its $\pi-\pi$ interaction peak $(704 \mathrm{~nm})$ displayed gradual enhancement. This observation also suggests thermal annealing can enhance $\pi-\pi$ interaction peak among SM-DPP6T molecules. But when the film was further treated at $120^{\circ} \mathrm{C}$, the absorbance of the whole spectrum including that of $\pi-\pi$ interaction peak decreased. This may be closely related to the formation of big crystals here and there in the film, as evidenced in the bellow AFM observation, which resulted in uneven distributed film thickness. And, it is valuable to point out that the vertex of this $\pi-\pi$ interaction peak slightly redshifted upon thermal annealing, from $704 \mathrm{~nm}$ for as cast to $706 \mathrm{~nm}$ after annealed at $80^{\circ} \mathrm{C}$, then to $708 \mathrm{~nm}$ after annealed at 100 and $120^{\circ} \mathrm{C}$. It would be another proof for the reinforcement of $\pi-\pi$ interactions among the molecules after thermal annealing.

In AFM microscopy (Fig. 5), the as-casted PRC-DPP6T film on OTS-treated $\mathrm{Si} / \mathrm{SiO}_{2}$ wafer displayed a structureless topographical height image with a root-mean-square (RMS) roughness of $7.12 \mathrm{~nm}$. When this film was subjected to thermal annealing, the RMS roughness changed to $3.53 \mathrm{~nm}$ at $80{ }^{\circ} \mathrm{C}, 1.99 \mathrm{~nm}$ at $120{ }^{\circ} \mathrm{C}$, and then to $1.34 \mathrm{~nm}$ at $140{ }^{\circ} \mathrm{C}$, proving the film became smoother and smoother. After further annealing at 160 and $180{ }^{\circ} \mathrm{C}$, fibrillary aggregates developed and the film became rougher with RMS roughness of 1.36 and $2.47 \mathrm{~nm}$, respectively. Since fibre structures are generally good for charge transportation, it is reasonable to observe mobility enhancement for this PRC-DPP6T film upon thermal annealing. However, when the annealing temperature reached $200{ }^{\circ} \mathrm{C}$, homogeneous and continuous topography disappeared. Alternatively, particle-like morphology was observed in place. Obviously, such film is unfavourable for FET performance, and thus cause performance drop. Since the melting point of PRC-DPP6T is $167^{\circ} \mathrm{C}$ as measured by DSC, this morphology change may be closely associated with such melting behaviour. In comparison, the AFM image of as-casted SM-DPP6T film on OTS-treated $\mathrm{Si} / \mathrm{SiO}_{2}$ wafer was full of particle (could be assigned to nanocrystals)-like species. Such particles grew bigger when the film was annealed at $60{ }^{\circ} \mathrm{C}$, and then started to merge together at 80 and $100{ }^{\circ} \mathrm{C}$. During these annealing processes, the surface RMS roughness changed from $1.40 \mathrm{~nm}$ for as cast film, to $2.69 \mathrm{~nm}$ for $60{ }^{\circ} \mathrm{C}$ annealing, then to 2.12 and $1.57 \mathrm{~nm}$ for annealing at 80 and $100{ }^{\circ} \mathrm{C}$ respectively. Higher annealing at $120{ }^{\circ} \mathrm{C}$ caused an amazing change in film morphology, which was full with big crystalline objects having clear edges. This made the film not consecutive anymore and resulted in dramatically drop in its FET performance. Since this annealing temperature $\left(120^{\circ} \mathrm{C}\right)$ is close to SM-DPP6T melting point $\left(131{ }^{\circ} \mathrm{C}\right.$ measured by DSC), such behaviours are reasonably correlated with melting properties of the material.

\section{Conclusions}

In summary, a poly(rod-coil) strategy has been demonstrated here to improve film formation properties for small molecular field-effect transistors without sacrifice in mobility. As a typical example of small molecular semiconductors, SM-DPP6T is suffering from the difficulty in formation of homogeneous films on OTS-treated $\mathrm{Si} / \mathrm{SiO}_{2}$ with even-distributed active material, and thus hard to ensure fabrication success rate for its OFET device preparation. Furthermore, even for the fabricated devices based on those films having a surface coverage $>95 \%$, an extremely wide mobility distribution has been found. However, all these shortages can be overcome by interconnecting its conjugated core segments with flexible butylene chains and changing its structure into poly(rod-coil) polymer. More interestingly, the resultant poly(rod-coil) polymer, PRC-DPP6T, achieved a mobility up to $0.17 \mathrm{~cm}^{2} \mathrm{~V}^{-1} \mathrm{~s}^{-1}$, which is comparable to the best performance of SM-DPP6T devices $\left(0.15 \mathrm{~cm}^{2} \mathrm{~V}^{-1} \mathrm{~s}^{-1}\right)$. Moreover, the change to poly(rod-coil) polymer also enhance material melting point, which lead to an improved heatresistant property for the devices. Considering a huge number of small molecular organic semiconductors reported in 
literature, this poly(rod-coil) strategy would open a new avenue for design and development of new polymeric types of organic semiconductors, which are highly potential to combine the merits of both small molecular and polymer materials: definite optoelectronically active conjugated core structure and good film formation property.

\section{Conflicts of interest}

There are no conflicts to declare.

\section{Acknowledgements}

This work was financially supported by National Natural Science Foundation of China (No. 21474129, 21674125, and 51761145043), International Science and Technology Cooperation Program of China (No. 2015DFG62680), Strategic Priority Research Program of Chinese Academy of Sciences (No. XDB20020000), Science and Technology Open Cooperation Projects of Henan Province (No. 162106000018 and 172106000067) and Zhengzhou Institute of Technology. The authors thank BL14B1 beam line of Shanghai Synchrotron Radiation Facility.

\section{Notes and references}

1 D. Brage and G. Horowitz, Adv. Mater., 2009, 21, 1473.

2 J. E. Anthony, A. Facchetti, M. Heeney, S. Marder and X. Zhan, Adv. Mater., 2010, 22, 3876.

3 C. Wang, H. Dong, W. Hu, Y. Liu and D. Zhu, Chem. Rev., 2012, 112, 2208.

4 H. Dong, X. Fu, J. Liu, Z. Wang and W. Hu, Adv. Mater., 2013, 25, 6158.

5 Y. Zhao, Y. Guo and Y. Liu, Adv. Mater., 2013, 25, 5372.

6 H. Sirringhaus, Adv. Mater., 2014, 26, 1319.

7 X. Gao and Y. Hu, J. Mater. Chem. C, 2014, 2, 3099.

8 H. Chen, Chin. J. Org. Chem., 2016, 36, 460.

9 Y.-J. Cheng, S.-H. Yang and C.-S. Hsu, Chem. Rev., 2009, 109, 5868.

10 A. Mishra and P. Bäuerle, Angew. Chem., Int. Ed., 2012, 51, 2020.

11 H. Ye, W. Li and W. Li, Chin. J. Org. Chem., 2012, 32, 266.

12 L. Dou, Y. Liu, Z. Hong, G. Li and Y. Yang, Chem. Rev., 2015, 115, 12633.

13 L. Lu, T. Zheng, Q. Wu, A. M. Schneider, D. Zhao and L. Yu, Chem. Rev., 2015, 115, 12666.

14 H. Yao, L. Ye, H. Zhang, S. Li, S. Zhang and J. Hou, Chem. Rev., 2016, 116, 7397.

15 A. C. Grimsdale, K. L. Chan, R. E. Martin, P. G. Jokisz and A. B. Holmes, Chem. Rev., 2009, 109, 897.

16 K. T. Kamtekar, A. P. Monkman and M. R. Bryce, Adv. Mater., 2010, 22, 572.

17 S. Gong, C. Yang and J. Qin, Chem. Soc. Rev., 2012, 41, 4797.

18 X. Yang, G. Zhou and W.-Y. Wong, Chem. Soc. Rev., 2015, 44, 8484.

19 F. Wang, Y. Tao and W. Huang, Acta Chim. Sin., 2015, 73, 9.

20 C. Zhang, P. Chen and W. Hu, Small, 2016, 12, 1252.
21 X. Zhan, A. Facchetti, S. Barlow, T. J. Marks, M. A. Ratner, M. R. Wasielewski and S. R. Marder, Adv. Mater., 2011, 23, 268.

22 B. J. Jung, N. J. Tremblay, M.-L. Yeh and H. E. Katz, Chem. Mater., 2011, 23, 568.

23 C. B. Nielsen, M. Turbiez and I. McCulloch, Adv. Mater., 2013, 25, 1859.

24 E. Wang, W. Mammo and M. R. Andersson, Adv. Mater., 2014, 26, 1801.

25 Q. Miao, Adv. Mater., 2014, 26, 5541.

26 H. Minemawari, T. Yamada, H. Matsui, J. Tsutsumi, S. Haas, R. Chiba, R. Kumai and T. Hasegawa, Nature, 2011, 475, 364.

27 B. Sun, W. Hong, Z. Yan, H. Aziz and Y. Li, Adv. Mater., 2014, 26, 2636.

28 G. Kim, S.-J. Kang, G. K. Dutta, Y.-K. Han, T. J. Shin, Y.-Y. Noh and C. Yang, J. Am. Chem. Soc., 2014, 136, 9477.

29 J.-H. Dou, Y.-Q. Zheng, Z.-F. Yao, T. Lei, X. Shen, X.-Y. Luo, Z.-A. Yu, S.-D. Zhang, G. Han, Z. Wang, Y. Yi, J.-Y. Wang and J. Pei, Adv. Mater., 2015, 27, 8051.

30 J. Y. Back, H. Yu, I. Song, I. Kang, H. Ahn, T. J. Shin, S.-K. Kwon, J. H. Oh and Y.-H. Kim, Chem. Mater., 2015, 27, 1732 .

31 M. Yamagishi, J. Takeya, Y. Tominari and Y. Nakazawa, Appl. Phys. Lett., 2007, 90, 182117.

32 H.-R. Tseng, H. Phan, C. Luo, M. Wang, L. A. Perez, S. N. Patel, L. Ying, E. J. Kramer, T.-Q. Nguyen, G. C. Bazan and A. J. Heeger, Adv. Mater., 2014, 26, 2993.

33 O. D. Jurchescu, M. Popinciuc, B. J. v. Wees and T. T. M. Palstra, Adv. Mater., 2007, 19, 688.

34 B. Kang, R. Kim, S. B. Lee, S.-K. Kwon, Y.-H. Kim and K. Cho, J. Am. Chem. Soc., 2016, 138, 3679.

35 H.-J. Li, J.-T. Wang, C.-Y. Mei and W.-S. Li, Chem. Commun., 2014, 50, 7720.

36 W. Shao, L. Liang, X. Xiang, H.-J. Li, F.-G. Zhao and W.-S. Li, Chin. J. Chem., 2015, 33, 847.

37 X. Xiang, W. Shao, L. Liang, X.-Q. Chen, F.-G. Zhao, Z. Lu, W. Wang, J. Li and W.-S. Li, RSC Adv., 2016, 6, 23300.

38 A. Gasperini, S. Bivaud and K. Sivula, Chem. Sci., 2014, 5, 4922.

39 A. Gasperini, X. A. Jeanbourquin, A. Rahmanudin, X. Yu and K. Sivula, Adv. Mater., 2015, 27, 5541.

40 Y. Zhao, X. Zhao, Y. Zang, C.-a. Di, Y. Diao and J. Mei, Macromolecules, 2015, 48, 2048.

41 Y. Zhao, X. Zhao, M. Roders, G. Qu, Y. Diao, A. L. Ayzner and J. Mei, Chem. Mater., 2015, 27, 7164.

42 B. C. Schroeder, Y.-C. Chiu, X. Gu, Y. Zhou, J. Xu, J. Lopez, C. Lu, M. F. Toney and Z. Bao, Adv. Electron. Mater., 2016, 1600104.

43 Y. Zhao, X. Zhao, M. Roders, A. Gumyusenge, A. L. Ayzner and J. Mei, Adv. Mater., 2017, 29, 1605056.

44 Y. Li, S. P. Singh and P. Sonar, Adv. Mater., 2010, 22, 4862. 45 Y. Li, P. Sonar, S. P. Singh, M. S. Soh, M. v. Meurs and J. Tan, J. Am. Chem. Soc., 2011, 133, 2198.

46 Y. Li, P. Sonar, S. P. Singh, W. Zeng and M. S. Soh, J. Mater. Chem., 2011, 21, 10829. 
47 J. S. Lee, S. K. Son, S. Song, H. Kim, D. R. Lee, K. Kim, M. J. Ko, D. H. Choi, B. Kim and J. H. Cho, Chem. Mater., 2012, 24, 1316.

48 C. Li, Z. Mao, H. Chen, L. Zheng, J. Huang, B. Zhao, S. Tan and G. Yu, Macromolecules, 2015, 48, 2444.

49 J. Lee, A.-R. Han, H. Yu, T. J. Shin, C. Yang and J. H. Oh, J. Am. Chem. Soc., 2013, 135, 9540.

50 M. J. Cho, J. Shin, S. H. Yoon, T. W. Lee, M. Kaur and D. H. Choi, Chem. Commun., 2013, 49, 7132.

51 J. Y. Back, H. Yu, I. Song, I. Kang, H. Ahn, T. J. Shin, S.-K. Kwon, J. H. Oh and Y.-H. Kim, Chem. Mater., 2015, 27, 1732 .
52 S. Park, J. Cho, M. J. Ko, D. S. Chung and H. J. Son, Macromolecules, 2015, 48, 3883.

53 M. Kirkus, L. Wang, S. Mothy, D. Beljonne, J. Cornil, R. A. J. Janssen and S. C. J. Meskers, J. Phys. Chem. A, 2012, 116, 7927.

54 C.-Y. Mei, L. Liang, F.-G. Zhao, J.-T. Wang, L.-F. Yu, Y.-X. Li and W.-S. Li, Macromolecules, 2013, 46, 7920.

55 L. Liang, J.-T. Wang, X. Xiang, J. Ling, F.-G. Zhao and W.-S. Li, J. Mater. Chem. A, 2014, 2, 15396.

56 L. Liang, X.-Q. Chen, L.-N. Liu, J. Ling, X. Xiang, W.-J. Xiao, C.-W. Ge, F.-G. Zhao, G. Xie, Z. Lu, J. Li and W.-S. Li, Tetrahedron, 2016, 72, 4329. 